\title{
EDitorial \\ EDitorial
}

\section{ESTADO, POLÍTICA SOCIAL E REGRESSÃO DE DIREITOS}

\author{
Alzira Maria Baptista Lewgoy* \\ Ana Paula Ornellas Mauriel ${ }^{* *}$ \\ Maria Liduína de Oliveira e Silva*** \\ Renato dos Santos Veloso ${ }^{* * * *}$
}

É com grande satisfação que apresentamos o $34^{\circ}$ volume da Revista Temporalis, cujo tema se dedica ao debate sobre as funções e configurações do Estado e das políticas sociais no contexto atual de crise capitalista e seus desdobramentos sobre a "questão social", considerando a regressão de direitos advinda com a entrada do neoliberalismo no país a partir dos anos 1990, agudizada a partir dos desafios conjunturais recentes, e no Brasil, com a nova onda de contrarreformas motivada pelo contexto pós-golpe de 2016.

\footnotetext{
* Assistente Social, mestre e doutora em Serviço Social pela PUCRS. Professora do curso de Serviço Social Universidade Federal do Rio Grande do Sul (UFRGS).

** Assistente Social e Mestre em Serviço Social pela UFRJ, Doutora em Ciências Sociais pela Universidade de Campinas (UNICAMP). Professora da Escola de Serviço Social da Universidade Federal Fluminense (UFF).

*** Assistente Social, Mestre e Doutora em Serviço Social pela PUCSP. Professora no curso de Serviço Social da Universidade Federal de São Paulo (Unifesp).

**** Assistente Social, Mestre e Doutor em Serviço Social pela UFRJ. Professor da Faculdade de Serviço Social da Universidade do Estado do Rio de Janeiro (UERJ).
} 
Desde sua chamada, a temática desta edição contou com grande atenção e contribuição de pesquisadores da área de política social e afins que buscam entender os determinantes estruturais e conjunturais colocados pelos processos avassaladores de destruição de direitos em curso, compreendendo-os como fundamentais para o Serviço Social, contribuindo não só para a ampliação dos debates e da socialização da produção de conhecimento da área de Serviço Social e afins, mas também para oferecer subsídios para a formação e exercício profissional de assistentes sociais inseridos nos diferentes espaços sócio-ocupacionais nas políticas sociais.

O Estatuto da Associação Brasileira de Ensino e Pesquisa em Serviço Social (ABEPSS), revisado e aprovado em 1998, reafirma como uma das finalidades desta Associação "estimular a publicação semestral da Revista Temporalis como revista nacional da ABEPSS" (ABEPSS, 1998). Dando continuidade ao esforço coletivo das gestões anteriores de indexação e qualificação da revista, a atual diretoria da ABEPSS, ciente da relevância e essencialidade deste objetivo, além de manter a política de uma comissão editorial composta por membros para além da diretoria, conduziu a discussão sobre a sustentabilidade da Temporalis na Assembleia extraordinária realizada na Oficina Nacional da ABEPSS dia 07 de novembro de 2017, na Universidade Federal Fluminense. Após informes e debates sobre o ponto, ficou deliberado que a revista Temporalis se manterá apenas online a partir deste número. Tal medida se faz necessária tanto pelos custos financeiros da revista impressa e sua distribuição, como por primar por uma política de divulgação mais abrangente, ampliando o acesso deste periódico aos leitores/as do Serviço Social e áreas afins.

O presente volume, sob o tema Estado, política social e regressão de direitos, expressa não só um debate urgente e necessário, mas um anseio da categoria já indicado pelo Grupo Temático de Pesquisa de Política Social e Serviço Social em seus colóquios e mesa temática realizada no último ENPESS em 2016, em Ribeirão Preto. Respondendo a essas demandas, este volume abriga, em sua maioria, artigos temáticos relacionando o tema do Estado, das políticas sociais e a atual conjuntura nacional e internacional, levando em conta as transformações ocorridas com a crise capitalista, a hegemonia neoliberal, a financeirização, os impactos 
nas classes trabalhadoras, considerando as particularidades dessas mudanças no capitalismo dependente latino-americano e brasileiro.

Cabe salientar que o modo de ser da política social no capitalismo maduro vem acompanhado de uma severa ofensiva sobre o trabalho naperspectiva de ampliaras taxas delucro, o que consequentemente implica em pressão para ampliação das condições de exploração do trabalho, por meio de flexibilizações, terceirização, informalização, dentre outras formas de precarização estrutural do trabalho e dos meios de vida dos trabalhadores, que trazem como resultantes o aumento da superpopulação relativa e do pauperismo, impactando na forma das políticas sociais que tendem a orquestrar ações de gerenciamento da pobreza, contribuindo para mistificar material e ideologicamente o solapamento dos direitos sociais e a perda da proteção social.

No Brasil, a opção por um modelo econômico ortodoxo, que seguiu à risca a agenda neoliberal administrada pelos organismos multilaterais, demonstra uma vinculação direta entre a política social e o capital que porta juros, seja por meio das desvinculações e constrangimentos orçamentários, seja por meio da monetarização, bancarização e remuneração direta dos bancos pelos serviços prestados, contribuindo para que os princípios da não implementada Seguridade Social constitucionalmente projetada sejam aniquilados.

Manipulando essas tendências estruturais e conjunturais está o Estado capitalista, trincheira de proteção estratégica da ordem da propriedade privada e da acumulação privada da riqueza socialmente produzida, que tem no centro desta zona estratégica a classe dominante (IASI, 2013). De modo violento, mas ao mesmo tempo mistificado em múltiplas ideologias, o uso adequado da violência para manutenção da dominação burguesa vem sendo apresentado como legítimo, numa nova síntese de coerção e consenso, onde as políticas sociais de gotejamento possuem papel chave.

Contudo, as contradições dessa sociabilidade vêm provocando também rebeldias, resistências e enfrentamentos, que vão desde movimentos sociais e formas de lutas com pautas coletivas à miserabilidade e aos crimes que se tornam "incômodos" sociais 
para onde se voltam ações de segurança e assistência social públicas.

Reverberando essas questões, a revista 34 está organizada em duas seções. A primeira delas formada por Artigos Temáticos engloba debates diretamente vinculados à chamada temática desta edição e a segunda organizada por uma seção de Temas Livres.

O texto que abre esta edição é de Jaime Osorio cuja preocupação central é entender como se estabelecem os elementos que determinam e definem o Estado e o poder político no capitalismo de forma geral, para daí caracterizar as bases do que classifica como Estado dependente. Para isso, toma por base a relação entre Estado e sociedade civil e a distinção entre Estado e aparato de Estado para explicar emergência, potencialidades e limitações dos chamados governos populares na América Latina.

Em "Capitalismo dependente, neoliberalismo e financeirização das políticas sociais no Brasil”, Tatiana Brettas aborda os mecanismos que contribuíram para a financeirização das políticas sociais no Brasil no contexto do neoliberalismo, resgatando aspectos da formação sócio-histórica brasileira que contribuem para a análise dos marcos da dependência e seus elementos estruturais. A autora busca, sem perder de vista as marcas estruturais de nossa economia dependente, identificar algumas das novidades conjunturais trazidas pelo neoliberalismo.

No artigo "O Fundo Público e a Superexploração do trabalho no Brasil", Renata Gomes da Costa aborda o fundo público como uma mediação decisiva no capitalismo, por possuir uma função central no processo de valorização ao participar de forma direta e indireta da produção de mais-valia. Para pensar as particularidades de como o fundo público financia as políticas sociais no Brasil, busca aportes na Teoria Marxista da Dependência (TMD), a fim de realizar as mediações necessárias que expliquem as contradições, limites e possibilidades do financiamento das políticas sociais no capitalismo dependente. Como a produção de mais-valia no Brasil carrega a marca da dependência, a superexploração do trabalho aparece como chave explicativa central para o entendimento da lei do valor e do fundo público em nossa realidade. 
Erika Cordeiro do Rego Barros Valentim e Juliane Feix Peruzzo realizam uma crítica ao empreendedorismo no artigo "A ideologia empreendedora: ocultamento da questão de classe e sua funcionalidade ao capital". As autoras realizam uma pesquisa teórica e demonstram como o empreendedorismo, enquanto ideologia do capital, impacta diretamente sobre o reconhecimento do pertencimento da classe trabalhadora. Partindo das obras centrais de Schumpeter, pensador considerado de maior relevância teórico-conceitual na definição do empreendedorismo e do indivíduo empreendedor, fazem uma confrontação teórica e política dessa perspectiva com as ideias de Marx, com destaque para a centralidade da categoria classe trabalhadora e sua validade na contemporaneidade, afirmando-a enquanto mediação fundamental para a compreensão do significado e sentido da ideologia empreendedora no contexto da luta de classes.

No artigo "Aproximações críticas ao conceito de equidade presente nos documentos da Cepal e do Banco Mundial”, Paloma Ravylla de Miranda Lima e Jordeana Davi abordam as concepções desenvolvidas contemporaneamente para o enfrentamento à "questão social", particularmente no âmbito da região latinoamericana. Para tanto, realizam uma pesquisa bibliográfica e documental para analisar as propostas e recomendações contidas nos documentos da Cepal e do Banco Mundial acerca da equidade, conceito-chave na reconfiguração do marco teórico das políticas sociais adotado no contexto das contrarreformas iniciadas nos anos 1990.

Fornecer elementos para uma crítica marxista à economia política da contrarreforma previdenciária é o objetivo de Thais Soares Caramuru, no artigo "Uma crítica marxista à economia política da contrarreforma previdenciária". Partindo da violenta ofensiva capitalista contra as condições de vida, trabalho e proteção social da classe trabalhadora brasileira, a autora sustenta que, no caso da Seguridade Social, mais precisamente da Previdência, o ataque burguês visa à imposição de uma drástica restrição do acesso a esta política social por parte de amplos contingentes de trabalhadores.

Trazendo o debate sobre a destrutividade socioambiental e os limites do capital, Leticia Soares Nunes, no artigo "A questão 
socioambiental na contemporaneidade: caráter destrutivo da acumulação capitalista", reflete sobre a conjuntura brasileira e os graves problemas socioambientais que vem assolando o país, potencializados por uma política ambiental que responde aos interesses do grande capital. A autora parte do pressuposto de que a agenda socioambiental brasileira vem privilegiando 0 discurso do consumo consciente e das saídas técnicas enquanto principais estratégias para "compatibilizar" produção da riqueza com sustentabilidade social e ambiental no capitalismo, conteúdos alinhados com as orientações dos organismos internacionais. Salienta no texto que as relações sociais capitalistas são a causa principal da crise socioambiental contemporânea, visto o distanciamento do homem e da natureza, a utilização classista dos recursos naturais e o uso irracional do mundo natural. Da mesma forma, a gestão ambiental pública brasileira vem estabelecendo estratégias que estão submetidas à mesma lógica do capital para obtenção de lucro, não interferindo nas causas da crise.

No artigo "Questão ambiental e precarização do trabalho a partir da realidade do lixão Iguatu - Ceará", Maria Wiliana Alves Lucas, Evelyne Medeiros Pereira, Luana Paula Moreira Santos abordam a questão ambiental como uma das expressões da "questão social" e suas implicações nos processos de precarização de vida e trabalho de catadores e catadoras de materiais recicláveis daquela localidade. As autoras apreendem as contradições inerentes a este cotidiano de trabalho e os desafios impostos a esses sujeitos, associadas à dinâmica atual do padrão de (re)produção capitalista, aos reflexos no mundo do trabalho e a ausência de uma política pública efetiva de gestão de resíduos sólidos em âmbito municipal, conforme preconiza a Política Nacional de Resíduos Sólidos.

No contexto da Política Nacional de Assistência Social, Robson Roberto Silva no artigo "Os projetos de Assistência Social em disputa e o padrão híbrido de gestão do SUAS" desenvolve análise sobre a construção da assistência social no Brasil, enquanto política pública, a partir do tensionamento entre distintos projetos nessa política, alinhados a projetos antagônicos de sociedade desde o início da chamada "Nova República". Diante disso, desde meados dos anos de 1990 vem sendo organizado um padrão híbrido de gestão, cujos principais traços de continuidade e rupturas são 
apresentados neste trabalho no período de construção do Sistema Único de Assistência Social (SUAS).

Cilene Sebastiana Braga e Mayra Ferreira Soares no artigo "Família e violações de direitos sociais no sudeste do Pará" refletem a relação entre família e política social na particularidade da assistência social, tendo como foco as violações de direitos sociais encontradas no âmbito do trabalho infantil, violência sexual e negligências, chamando atenção para a forte responsabilização das mulheres e famílias nessas situações de violências.

No artigo "Crianças e adolescentes: o sistema de proteção social em Pernambuco”, Elisa Celina Alcantara Carvalho Mélo e Nathália Gregório dos Santos analisam os tipos de violações de direitos a crianças e adolescentes atendidas nos CRAS e CREAS do Estado de Pernambuco. Para realizar tal reflexão, além de pesquisa bibliográfica, foram coletados dados das planilhas anuais sobre os relatórios mensais de atendimentos dos CRAS e CREAS de 2016 no site do Ministério de Desenvolvimento Social e Combate à Fome - MDS. Diante dos dados e análises apresentadas, as autoras destacam que mesmo diante dos avanços legais trazidos por meio da Constituição Federal de 1988 e do Estatuto da Criança e do Adolescente em 1990, os índices e as formas de violações de direitos cometidas contra crianças e adolescentes são alarmantes.

O artigo "População em situação de rua: crise do capital e o desmonte das políticas públicas" de Erika dos Santos Tolentino e Valeria Pereira Bastos articula os impactos da crise atual do capital no Brasil, as consequências para as políticas sociais, a diminuição de financiamento público, a redução de direitos sociais e os desdobramentos para as camadas mais pobres da classe trabalhadora com o que ocorre com a população de rua no país. Trata-se de um estudo teórico, considerando a teoria marxiana, a partir da Lei Geral de Acumulação Capitalista no livro I de O Capital, identificando-a no conjunto de pessoas que atualmente compõem a superpopulação relativa estagnada do exército industrial de reserva. O texto expõe esses elementos em dois momentos, no primeiro, procede uma breve análise sobre a crise econômica e política atual; no segundo discorre sobre a população em situação de rua, correlacionando com a categoria de superpopulação relativa 
estagnada e os rebatimentos vividos pela população de rua em decorrência do acirramento da crise, relacionando o atendimento dos seus direitos pelo Estado no âmbito das políticas sociais.

O artigo "Morador de Rua: causas, entraves e serviços ofertados" compõe o eixo temático da assistência social apresentando um estudo da realidade dos moradores de rua a partir do público atendido nas unidades de serviço de atendimento aos moradores de rua em Montes Claros - Minas Gerais (no Centro de Referência Especializado para População em Situação de Rua - Centro Pop, o Serviço Especializado em Abordagem Social e o Consultório na Rua). As autoras Elucleia Oliveira Balieiro, Carla Patrícia Dias Soares e Eliana de Araújo Vieira apresentam, por meio das narrativas de moradores de rua e de profissionais das unidades/serviço suprareferidos, como a pessoa que reside na rua utiliza o espaço da rua ou albergues públicos para pernoite, e quais são as perspectivas de saída por parte de moradores de rua da situação na qual se encontram, tomando como referência os serviços públicos ofertados a este fim.

No contexto da política de Saúde, Edvânia Ângela de Souza Lourenço retrata através da pesquisa "Trabalho e saúde das assistentes sociais da área da saúde" a relação trabalho e saúde de assistentes sociais que atuam nos serviços de saúde, expondo o perfil dos profissionais, os locais onde atuam, as principais formas de contratação, de salário, bem como os elementos constitutivos para a realização no trabalho. Os resultados evidenciaram que há questões que interatuam para o processo de sofrimento no e pelo trabalho, que há forte presença dos modelos privados na gestão dos serviços de saúde do SUS, contratação por meio de processo seletivo e de indicação, baixos salários, pressão para não aceitação à jornada de 30 horas, uma conquista da categoria profissional em 2010, mostrando um quadro de precarização geral das condições de trabalho de assistentes sociais que atuam nessa política.

O artigo “Vida nua' e Estado de exceção: as penitenciárias de Mato Grosso", de Cíntia Lopes Branco e Imar Domingos Queiroz, analisa as condições de vida nas penitenciárias de Mato Grosso,correlacionando essa realidade aos direitos previstos nas legislações vigentes da área. As análises descortinam as condições 
de vida e a prevalência de medidas de exceção no sistema penitenciário, que alimentam o caos e transformam territórios e os sujeitos de direitos em pessoas descartáveis, passíveis de serem exterminadas.

No âmbito da Educação Superior as autoras Mônica Duarte Cavaignac e Renata Maria Paiva da Costa mostram no artigo "Serviço Social, Assistência Estudantil e Contrarreforma do Estado" uma análise do trabalho profissional na área da educação, especificamente no âmbito da assistência estudantil, a partir de um estudo com assistentes sociais do Instituto Federal de Educação, Ciência e Tecnologia do Ceará (IFCE). As autoras apontam os principais desafios e perspectivas dos/as profissionais num cenário marcado pela contrarreforma do Estado, pelo desmonte das políticas sociais públicas e pela negação dos direitos sociais, que impõe limites ao exercício profissional da categoria, dificultando a efetivação da política de assistência estudantil, comprometendo, assim, o acesso à educação como um direito.

A análise da atuação contemporânea da Bancada Ruralista no Congresso Nacional como uma expressão singular do avanço do conservadorismo na política brasileira é o objetivo de Elizângela Cardoso de Araújo Silva, no artigo "Conservadorismo, Bancada Ruralista e Indígenas". A autora trata dos principais desdobramentos dessa conjuntura para a relação entre Estado e questão indígena, discutindo os desafios dos povos originários para o enfrentamento do conservadorismo nos processos de resistência de luta pela terra. A partir de pesquisa bibliográfica e documental, a autora interpreta as expressões do conservadorismo em instâncias peculiares da esfera institucional da política brasileira, demonstrando que a constituição da Bancada Ruralista tem na base de sua atuação o projeto da classe dominante que atinge objetivamente as condições de vida dos povos indígenas, com a regressão de direitos e o acirramento dos conflitos no campo.

Iniciando a seção de Temas Livres a pesquisa bibliográfica de Maiara Lopes da Silva no artigo "Reificações da "questão social": armadilhas do capital em tempos de crise estrutural", toma como objeto de investigação a "questão social", objetivando problematizar suas reificações frente ao contexto de crise 
estrutural do sistema sociometabólico do capital, indica como tal processo de mistificação vem rebatendo no Serviço Social e como a profissão precisa enfrentá-lo. Nesse contexto, a autora indica a necessidade do/a assistente social ter o domínio histórico, teórico, metodológico, técnico e ético a respeito da "questão social" para não ser sucumbido pelas armadilhas do capital no seu "fazer profissional".

Cristiane Luiza Sabino Souza, no artigo "Cooperação antagônica e dupla articulação dependente: a dinâmica da luta de classes no Brasil", aborda os elementos centrais para a análise da reprodução social inerente ao desenvolvimento capitalista dependente, utilizando as categorias dupla articulação dependente de Florestan Fernandes e cooperação antagônica de Ruy Mauro Marini para evidenciar sua proximidade para a compreensão das contradições de classe sob a dependência estrutural. Segundo a autora, o acirrado avanço das burguesias nacionais e internacionais na disputa do excedente econômico para suprir a valorização do capital escancara a desigualdade política, social e econômica entre as classes, colocando na pauta do dia a necessidade de organização da classe trabalhadora, como meio de resistência à violação de direitos e aos mecanismos de sustentação da dependência.

O artigo “Produção do Conhecimento dos Cursos de Pós-Graduação em Serviço Social sobre Lutas, Organizações, Movimentos Sociais e Serviço Social", de Maria Lucia Duriguetto retrata o estado da arte da produção acadêmica das Teses de Doutorado e das Dissertações de Mestrado dos cursos de Pós-Graduação da Área Serviço Social no período de 1985 a 2011. A autora analisa a questão das lutas, organizações e movimentos sociais dos trabalhadore(a)s e sua relação com o Serviço Social e o trabalho profissional. Diante dos dados apresentados Duriguetto nos convoca a pensar sobre a tematização das relações do Serviço Social com o universo das lutas, organizações e movimentos sociais na produção acadêmica, na formação e no exercício profissional.

Marina Monteiro de Castro e Castro e Ana Maria Ferreira apresentam na pesquisa "Estágio Supervisionado em Serviço Social: reflexões a partir da realidade da Universidade Federal de Juiz de Fora" uma análise sobre a organização e a avaliação do processo de 
supervisão de estágio e seus desafios contemporâneos, bem como sobre as condições de trabalho dos profissionais, as características da política de estágio e a contribuição para a formação e o trabalho profissional. Os desafios apontados na pesquisa realizada estão atrelados a uma série de demandas postas pelo mercado que busca profissionais capazes de dar respostas imediatas e burocratizadas, muitas vezes vazias de compreensão crítica, e, ao mesmo tempo, a um conjunto de lutas pela urgência do fortalecimento do Projeto Ético Político Profissional, direção para o projeto de formação profissional, na defesa da Política Nacional de Estágio (PNE) e das resoluções do conjunto CFESS/CRESS acerca do estágio, apontando para a necessidade de organização e fortalecimento do processo de supervisão de estágio.

O artigo "Uma reflexão sobre as contribuições da arte nas lutas sociais", de Priscila Rodrigues Castro, elabora uma reflexão sobre as potencialidades artísticas presentes nas lutas sociais contemporâneas, a partir de um panorama sobre os processos de construção e estilos culturais estabelecidos com o capitalismo tardio fundamentados na teoria de Frederic Jameson. Destacando a ostensiva reação conservadora e fundamentalista às manifestações artísticas originárias das lutas sociais da classe trabalhadora, a autora defende o uso político da arte para potencializar as lutas coletivas e impedir o avanço do retrocesso na conquista de direitos e liberdades de fruição humanas.

Fechando esta edição, Micaela Alves Rocha da Costa, Lizete Augusta Vidal Pereira Lopes Silva, Andréa Lima da Silva, em “Agenda Feminista em construção e a direção emancipatória do conjunto CFESS/CRESS", analisam a contribuição política do conjunto CFESS/CRESS para a consolidação da luta feminista, étnico-racial e da diversidade sexual na formação e no exercício profissional, por meio de resoluções e publicações consideradas fundamentais para o pensar e o fazer profissional comprometidos com a classe trabalhadora. As autoras reconhecem a contribuição do conjunto CFESS/CRESS para a construção de uma cultura feminista com a perspectiva crítica, frente ao avanço do neoliberalismo e da pósmodernidade, mas também destacam os preocupantes ataques à direção política das entidades, os quais colocam em xeque as lutas feministas, de igualdade racial e de diversidade sexual que vêm se 
desenhando no âmbito profissional.

Esperamos que a leitura adense a crítica e aguce novas inspirações paraas lutas, pois como nos anuncia lasi (2017; p.437): “empenhemomos em ser os precursores de algo muito diverso do existente que se anuncia e que não virá sem nossos esforços".

Desejamos uma ótima leitura!!

"Quem é de luta, Resiste!"

Gestão 2017-2018

\section{REFERENCIAS}

Associação Brasileira de Ensino e Pesquisa em Serviço Social. ABEPSS. Estatuto. Brasília. 1998.

IASI, Mauro. O Estado e a violência. In: http://blogdaboitempo. com.br/2013/10/16/o-estado-e-a-violencia/. Acesso em $10 \mathrm{de}$ novembro de 2013.

IASI, Mauro. Política, Estado e ideologia na trama conjuntural. São Paulo: ICP, 2017. 